\title{
Erythema multiforme-like lesion: A COVID-19 manifestation?
}

\section{Priyanka Mainali, Deeptara Pathak Thapa}

Department of Dermatology and Venereology, Nepal Medical College Teaching Hospital, Attarkhel, Kathmandu, Nepal

Corresponding author: Priyanka Mainali, PG, E-mail: mainalip92@gmail.com

Sir,

COVID-19 is caused by severe acute respiratory syndrome coronavirus 2 (SARS-CoV-2). It was first reported as pneumonia in December 2019 in Wuhan, China. Since then, it has been spreading rapidly and WHO has declared it a pandemic on March 11 , 2020 [1]. As of October, COVID-19 had affected about 8,029,217 cases worldwide and 111,802 cases in Nepal alone. Cutaneous manifestations have been reported in 20\% of COVID-19 patients [2]. We report a case of erythema multiforme-like lesions in a young patient who was likely a case of a COVID-19 infection.

A 32-year-old male presented himself to our OPD with the chief complaints of fever and erythematous palpable rashes over the bilateral feet, legs, and hands persistent for one week. The mucous membranes were spared. The patient also complained of pain over the bilateral knee joint and fatigue. The patient gave no history of diarrhea, dyspnea, anosmia, or dysgeusia and no history of drug intake prior to the onset of lesions. A physical examination revealed an erythematous targetoid lesion distributed over the dorsum of the bilateral feet (Fig. 1) and the distal half of the bilateral legs and several lesions scattered over the dorsum of the bilateral hand and over the abdomen and back. A systemic examination was normal. The patient was clinically diagnosed with erythema multiforme minor.

On laboratory investigation, ESR was 40, CRP was positive $(+++)$, and ANA was 1:100. Other laboratory investigations, such as complete blood count, a renal function test, a liver function test, RA factor, and a urine routine examination, were normal. A chest X-ray revealed prominent bilateral pulmonary vessels and an otherwise normal chest.

As erythema multiforme is one of the cutaneous manifestations of COVID-19 and positive CRP is an important laboratory marker, the patient was advised RT-PCR, but denied it. Yet, the patient was counseled regarding the cutaneous manifestations and was advised home isolation.

New reports of COVID-19-related cutaneous manifestations are emerging rapidly. According to a study conducted by Daneshgaran et al., erythema multiforme-like eruptions account for $3.7 \%$ of the total cutaneous manifestations of COVID-19 [3]. Several case reports of erythema multiforme-like lesions in COVID-19 patients were published in the literature by Demirbas et al. [1], Garguilo et al. [4], Recalcati et al. [5], Torrelo et al. [6], and Janah et al. [7].

Most people are well aware about the fever and pulmonary manifestations of COVID-19 but the fact that COVID-19 can present other manifestations is still poorly recognized. Because of this, there may be skepticism around accepting a present COVID-19 infection that manifests itself in other ways and so there may be hesitance against taking confirmatory tests. We experienced the same situation with our patient, who had little knowledge regarding the cutaneous manifestations of COVID-19 and was hesitant to take a confirmatory test despite constant counseling.

Numerous positive cases remain undiagnosed due to the lack of awareness about the various manifestations

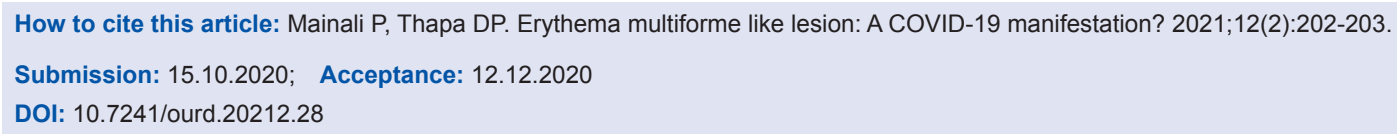




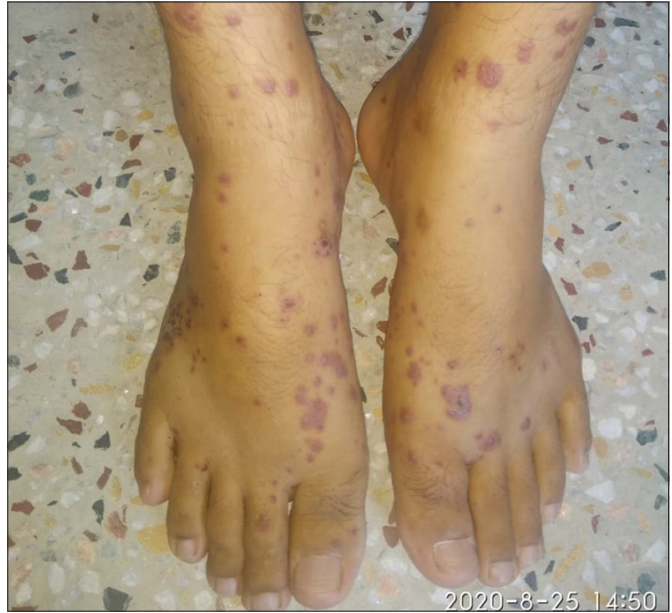

Figure 1: Multiple erythema multiforme-like lesions over the dorsum of the bilateral feet, ankles and, distal legs.

of the disease. Additionally, there appears a greater risk of spreading the disease in a community and, thus, a greater risk of an increased disease burden.

Proper knowledge about atypical cutaneous manifestations may help to increase surveillance and decrease the transmission of COVID-19 as a high index of suspicion is the major factor that brings a patient to the hospital for screening.

\section{Consent}

The examination of the patient was conducted according to the principles of the Declaration of Helsinki.
The authors certify that they have obtained all appropriate patient consent forms, in which the patients gave their consent for images and other clinical information to be included in the journal. The patients understand that their names and initials will not be published and due effort will be made to conceal their identity, but that anonymity cannot be guaranteed.

\section{REFERENCES}

1. Demirbaş A, Elmas ÖF, Atasoy M, Türsen Ü, Lotti T. A case of erythema multiforme major in a patient with COVID 19: The role of corticosteroid treatment. Dermatol Ther. 2020;e13899.

2. Adukia SA, Ruhatiya RS, Maheshwarappa HM, Manjunath RB, Jain GN. Extrapulmonary features of COVID-19: A concise review. Indian J Crit Care Med. 2020;24:575-80.

3. Daneshgaran G, Dubin DP, Gould DJ. Cutaneous manifestations of COVID-19: An evidence-based review. Am J Clin Dermatol. 2020;21:627-39.

4. Gargiulo L, Pavia G, Facheris P, Valenti M, Sacrini F, Narcisi A, et al. A fatal case of COVID-19 infection presenting with an erythema multiforme-like eruption and fever. Dermatol Ther. 2020;33:e13779.

5. Recalcati S, Barbagallo T, Frasin LA, Prestinari F, Cogliardi A, Provero MC, et al. Acral cutaneous lesions in the time of COVID-19. J Eur Acad Dermatol Venereol. 2020;34:e346-7.

6. Torrelo A, Andina D, Santonja C, Noguera-Morel L, BascuasArribas M, Gaitero-Tristán J, Alonso-Cadenas JA, EscaladaPellitero S, Hernández-Martín Á, de la Torre-Espi M, Colmenero I. Erythema multiforme-like lesions in children and COVID-19. Pediatr Dermatol. 2020;37:442-6.

7. Janah H, Zinebi A, Elbenaye J. Atypical erythema multiforme palmar plaques lesions due to SARS-CoV-2. J Eur Acad Dermatol Venereol. 2020;34:e373-5.

Copyright by Priyanka Mainali, et al. This is an open access article distributed under the terms of the Creative Commons Attribution License, which permits unrestricted use, distribution, and reproduction in any medium, provided the original author and source are credited.

Source of Support: Nil, Conflict of Interest: None declared. 